\title{
Close de Garota: A Representação da Mulher Transexual em Campanhas de Beleza
}

\author{
Girl Close-up: The Representation of Transsexual Women in Beauty Products \\ Ads
}

\section{Chica en Escena: La Representación de la Mujer Transexual en Publicidades de Belleza}

Renata Barreto Malta

Ruhan Victor Oliveira dos Santos ${ }^{2}$

Ana Alinny Cruz Reis ${ }^{3}$

\section{Resumo}

As relações entre publicidade, gênero e representação frequentemente convergem em um cenário de debates e contestações. A crítica a um modelo de produção publicitário que reforça os padrões hegemônicos de raça e dos binarismos compulsórios entre sexo e gênero tem sido contraposta a um movimento tímido e ainda recente por novos modelos de representação. Por meio do arcabouço teórico dos Estudos Culturais, esse artigo analisa a representação da mulher transexual em vídeos publicitários das marcas Redken, Clean \&Clear, MAC, Avon e L'oréal entre janeiro de 2015 a maio de 2016. Utilizando abordagem teórico-metodológica proposta por Bordwell (2008), buscamos compreender em qual contexto a mulher transexual é posicionada e quais significados podem ser percebidos na construção de uma narrativa ideológica sobre a experiência transexual.

\begin{tabular}{|c|c|}
\hline \multirow{3}{*}{ 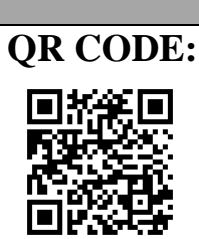 } & Acesse este artigo online \\
\hline & $\begin{array}{l}\text { Website: } \\
\text { http://www.revistas.ufg.br/index.php/ci }\end{array}$ \\
\hline & $\begin{array}{l}\text { DOI: } \\
\text { http://dx.doi.org/10.5216/ci.v20i1.45024 }\end{array}$ \\
\hline
\end{tabular}

Palavras-chave: Representação. Publicidade.
Identidade. Transexualidade.

\begin{abstract}
The relation between advertising, gender and representation often converges in a prospect of debates and contestations. Criticism of a model of advertising production, which reinforces the hegemonic patterns of race and compulsory binarism between sex and gender, has been placed in opposition to a modest and recent movement for new models of representation. Through the theoretic framework of Cultural Studies, this article analyses the representation of transsexual women in advertising videos of the brands Redken, Clean \& Clear, MAC, Avon and L'oréal between January 2015 and May 2016.

1 Doutora em Comunicação Social. Professora efetiva do Departamento de Comunicação Social da UFS (Universidade Federal do Sergipe). Professora Permanente do Programa de Pós Graduação Stricto Sensu em Comunicação Social (PPGCOM) da Universidade Federal de Sergipe vinculada à linha de pesquisa 1 - Produtos, Processos e Discursos Midiáticos. Coordenadora no Brasil do grupo de pesquisa CHISGAP (Critical, Historical and international Studies on Gender and Press). Brasil, Sergipe, Aracaju. E-mail: renatamaltarm@gmail.com

2 Mestrando em Comunicação Social pelo PPGCOM - Universidade Federal de Sergipe. Brasil, Sergipe, Aracaju. E-mail: ruhanvictorr@gmail.com

3 Mestranda em Comunicação Social pelo PPGCOM - Universidade Federal de Sergipe. Brasil, Sergipe, Aracaju. E-mail: alinnylinny@gmail.com
\end{abstract}

Comun. \& Inf., Goiânia, GO, v. 20, n. 1, p.73-91, jan./jun. 2017 
Applying the theoretical and methodological approach proposed by Bordwell (2008), it is intend to understand in which context the transsexual women are positioned and which meanings can be perceived in the creation of an ideological narrative concerning the transsexual experience.

Keywords: Identity. Representation. Transsexuality. Advertising.

\section{Resumen}

Las relaciones entre publicidad, género y representación frecuentemente convergen en un escenario de debate y contestaciones. La crítica a un modelo de producción publicitario que refuerza los padrones hegemónicos de raza y los binarismos compulsorios entre sexo y género ha sido contrapuesta a un movimiento tímido y aún reciente por nuevos modelos de representación. Por medio del marco teórico de los Estudios Culturales, este artículo analiza la representación de la mujer transexual en videos publicitarios de las marcas Redken, Clean \&Clear, MAC, Avon y L'oréal entre enero de 2015 y mayo de 2016. Utilizando abordaje teórico-metodológica propuesta por Bordwell (2008), buscamos entender en cual contexto la mujer transexual es posicionada y cuales significados pueden ser percibidos en la construcción de una narrativa ideológica sobre la experiencia transexual.

Palabras-clave: Identidad. Representación. Transexualidad. Publicidad.

\section{INTRODUÇÃO}

7 ste artigo se propõe a analisar a representação transexual em campanhas 7 femininas de beleza. No mundo, segundo um relatório do Bank of America Merril Lynch em 2015, o gasto global anual com produtos e serviços destinados a melhorar nossa aparência, confiança e prestígio é de US\$ 4,5 trilhões de dólares ${ }^{4}$.

Segundo a ABIHPEC (Associação Brasileira da Indústria de Higiene Pessoal, Perfumaria e Cosméticos) o Brasil é o quarto maior consumidor mundial no setor de higiene pessoal, perfumaria e cosméticos (HPPC), atrás apenas dos Estados Unidos, Japão e China. Em 2015 , o faturamento brasileiro nesse setor foi de $\mathrm{R} \$ 42,6$ bilhões $^{5}$; naturalmente, neste mesmo ano o mercado de HPPC foi também a indústria que mais investiu em comunicação e publicidade no Brasil, segundo o IBOPE ${ }^{6}$.

Já a transexualidade trava constantes lutas por visibilidade. A Organização Mundial de Saúde (OMS), por exemplo, agência subordinada à Organização das Nações Unidas (ONU), ainda considera a transexualidade como um transtorno mental ${ }^{7}$. O Brasil é o país que mais mata transexuais no mundo, fato que inclusive chega a viabilizar o termo transfeminicídio ${ }^{8}$; fato este que acontece, contraditoriamente, ao mesmo tempo em que Lea $\mathrm{T}$ foi a primeira transexual com

\footnotetext{
4 Disponível em: <http://exame.abril.com.br/economia/noticias/vaidade-e-a-4a-maior-economia-domundo>.

Disponível em: <https://www.abihpec.org.br/2016/04/setor-brasileiro-de-higiene-pessoal-perfumaria-ecosmeticos-sofre-queda-real-de-8-em-2015/>.

6 Disponível em: <https://www.abihpec.org.br/2015/05/marketing-da-beleza/>.

7 Disponível em: <http://brasil.elpais.com/brasil/2016/07/26/ciencia/1469530342_919740.html>.

8 Disponível em: 〈http://www.clam.org.br/uploads/arquivo/Transfeminicidio_Berenice_Bento.pdf .
}

Comun. \& Inf., Goiânia, GO, v. 20, n. 1, p.73-91, jan./jun. 2017 
papel de destaque em uma cerimônia de abertura olímpica, representando a delegação do Brasil no Rio $2016^{9}$.

É nesse contexto dual que publicidade e transexualidade se viabilizam. De janeiro de 2015 a maio de 2016, 18 peças de campanhas femininas de beleza foram protagonizadas por mulheres transexuais no mundo, cinco destas, inclusive, sendo brasileiras. Essas peças, que marcam por muitas vezes os primeiros contatos de grandes marcas do mercado de beleza com mulheres transexuais, são produções nacionais e internacionais de grandes empresas de produtos para cabelo e pele, nomes-chave do setor como Avon, L'oréal e MAC.

Historicamente, representação e transexualidade no cenário de campanhas femininas de beleza remetem a dois marcadores de significados e contextos, relembrados aqui para delimitação de um despretensioso histórico sobre o tema. O primeiro deles é a trajetória de Tracey Africa Norman, primeira modelo transexual e negra a protagonizar campanhas femininas para marcas como Avon e Clairol nos anos $1970^{10}$ nos USA. Tracey começou a tomar hormônios ao fim do ensino médio, e como "passava" facilmente como mulher cisgênero experimentou uma carreira relativamente longa na moda, até que sua condição de transexual fosse descoberta e isso culminasse em demissão.

O termo passabilidade, gíria transexual, é compreendido como o conjunto de características que fazem mulheres transexuais serem reconhecidas esteticamente como mulheres cisgênero, mulheres que nascem biologicamente mulheres. O segundo marco é a da bem-sucedida campanha em vídeo da cantora, modelo e atriz transexual sul-coreana Harisu para a marca Dodo Cosmetics, veiculada em 2001. Em um contexto exótico e humorístico, a modelo apresenta em poucos segundos uma base em pó que seria tão boa que poderia "disfarçar" sua condição como transgênero, relativizando o pomo de adão ${ }^{11}$. Tais exemplos foram citados como referenciais interpretativos, sendo a passabilidade e $\mathrm{o}$ fator humorístico/exótico importantes perspectivas de análise de contexto aos quais mulheres transexuais são constantemente associadas.

Para a pesquisa empírica proposta por este estudo, as 18 peças de campanhas femininas de beleza protagonizadas no mundo por mulheres transexuais de janeiro de 2015 a maio de 2016 foram submetidas a critérios específicos para definição do corpus de análise. Considerando que uma mesma campanha pode produzir tanto material impresso como

9 Disponível em: <http://www.bbc.com/portuguese/brasil-36912561〉.

Disponível em: <http://nymag.com/thecut/2015/12/tracey-africa-transgender-model-c-v-r.html>

Disponível em: <https://www.youtube.com/watch?v=gERNAwO_bsE>.

Comun. \& Inf., Goiânia, GO, v. 20, n. 1, p.73-91, jan./jun. 2017 
audiovisual, o primeiro recorte determinou um formato único de análise, o vídeo publicitário, que é por nós compreendido como um interessante formato para busca de significados.

Essa escolha também tem relação direta com o desenvolvimento metodológico deste artigo, que segue a proposta de análise de significados sugerida por Bordwell (2008). A partir daí, analisamos o primeiro vídeo das campanhas presentes nos canais oficias das marcas de beleza feminina com maior número de inscritos no YouTube.

Após essas delimitações, das 18 peças de campanhas femininas foram selecionadas cinco. Este artigo, portanto, se dedica a analisar a representação da mulher transexual em vídeos das campanhas de beleza das marcas Redken, Clean \& Clear, MAC, Avon, e L'oréal. O objetivo é investigar em quais contextos a mulher transexual tem sua participação veiculada, bem como quais significados podem ser percebidos na construção de uma narrativa ideológica sobre a experiência transexual. Ainda imperam a passabilidade de Tracey e o fator exótico de Harisu?

\section{PADRÃO HEGEMÔNICO E PRODUÇÃO PUBLICITÁRIA}

A ideia de hegemonia sugere processos de dominação e subordinação de significados, valores e crenças de uma determinada classe sob a outra. Williams (1979) define hegemonia como:

[...] Todo conjunto de práticas e expectativas sobre a totalidade da vida: nossos sentidos e distribuição de energia, nossa percepção de nós mesmos e nosso mundo. É um sistema vivido de significados e valores - constitutivo e constituidor - que, ao serem experimentados como práticas parecem confirmar-se reciprocamente. Constitui assim um senso da realidade para a maioria das pessoas na sociedade, um senso de realidade absoluta, porque experimentada, e além da qual é muito difícil para maioria das áreas de sua vida. Em outras palavras, é no sentido mais forte uma "cultura", mas uma cultura que tem de ser considerada como o domínio e subordinação vividos de determinadas classes (WILLIAMS, 1979, p.113).

A visão hegemônica é complexa e é sempre atualizada e redefinida, não somente na esfera econômica, de classes, mas também nas instâncias culturais e nas relações sociais. Contudo, embora a formação hegemônica seja um processo longo e represente intensas disputas históricas de poder, essas características não determinam necessariamente que não haja uma resistência, manifestações culturais contrárias a esse processo. Hall (2003) segue afirmando que:

A hegemonia cultural nunca é uma questão de vitória ou dominação pura (não é isso que o termo significa); nunca é um jogo cultural de perde-ganha; sempre tem a ver com mudança no equilíbrio de poder nas relações da cultura; tratase de mudar as disposições e configurações do poder cultural e não se retirar dele (HALL, 2003, p. 339). 
Esse equilíbrio de poder e de mudanças de posições tendem a surgir através de movimentos definidos como contra-hegemônicos, que buscam alterar o cenário de dominação sustentado pelo pensamento hegemônico, impulsionados pela diversidade de padrões como religião, raça e etnia, sexualidade, gênero e etc. Gramsci (apud MORAES, 2010, p. 73) descreve que movimentos contra-hegemônicos são instrumentos de alteração social com o objetivo de "denunciar e tentar reverter às condições de marginalização e exclusão impostas a amplos estratos sociais $[. .$.$] ].O contra-hegemônico é, portanto, como uma tensão, uma medição de$ forças históricas entre blocos de grupos sociais, que pode ser reelaborada, alterada e modificada.

Torna-se imprescindível, portanto, o papel da publicidade e dos próprios meios de comunicação na constituição de instrumentos essenciais na consolidação do hegemônico ou na luta por transformações contra-hegemônicas, criando rupturas em quadros de dominação. Moraes (2009), afirma:

Na essência, o discurso midiático se propõe a determinar a interpretação dos fatos por intermédio de signos fixos e constantes que tentam proteger de contradições aquilo que está dado e aparece como representação do real, como verdade. Tal discurso interfere preponderantemente na cartografia do mundo coletivo, propondo um conjunto de linhas argumentativas sobre a realidade, aceitas ou consideradas por amplos setores da sociedade (MORAES, 2009, p. 45).

A publicidade, como produção cultural, frequentemente reforça valores hegemônicos, e está diretamente associada à determinação de formações imaginárias e reprodução de ideias e estereótipos que funcionam como instrumento de organização social por serem historicamente carregados de julgamentos e pressupostos de comportamento de determinados grupos e pessoas. Em campanhas publicitárias, por exemplo, como larga parte desse contexto comunicacional, o hegemônico é também recortado por questões étnicas e de classe e é constantemente relacionado principalmente à supremacia da raça branca e do macho, que desfrutam de maior visibilidade e poder de representação.

A dominação masculina é aqui fator que merece destaque, podendo ser percebida em diversas áreas da sociedade, imbricada no inconsciente e nas formas mais simples de organização do pensamento e da linguagem. Bourdieu (1999) explora o assunto:

Inscrita nas coisas, a ordem masculina se inscreve também nos corpos através de injunções tácitas, implícitas nas rotinas da divisão do trabalho ou dos rituais coletivos ou privados. As regularidades da ordem física e da ordem social impõem e inculcam as medidas que excluem as mulheres das tarefas mais nobres..., assinalando-lhes lugares inferiores..., ensinando-lhes a postura correta do corpo... atribuindo-lhes tarefas penosas, baixas e mesquinhas (BOURDIEU, 1999, p. 34).

Comun. \& Inf., Goiânia, GO, v. 20, n. 1, p.73-91, jan./jun. 2017 
No caso das campanhas femininas de beleza, nicho deste artigo, é grande a tendência em associar a beleza a um tipo muito específico de feminilidade. Composta amplamente por um padrão hegemônico de mulheres brancas e cisgênero, com um grande apelo a corpos magros e características que evocam um significado estético bem definido do termo "mulher". Lipovetsky (1989) pondera que:

Os produtos cosméticos, as marcas de perfume em particular, recorrem sistematicamente a publicidades refinadas, sofisticadas colocando em certas criaturas sublimes perfis e maquiagem de sonho. Da mesma maneira que a moda não pode ser separada da estetização da pessoa, a publicidade funciona como cosmético da construção[...] (LIPOVETSKY, 1989, p.189)

A representação do próprio espaço da mulher na publicidade brasileira é uma questão essencialmente polêmica. Uma pesquisa ${ }^{12}$ do Instituto Patrícia Galvão aponta, por exemplo, que $65 \%$ das mulheres brasileiras não se identificam com a publicidade e com a forma como são retratadas. A pesquisa ainda aponta que apenas $10 \%$ dos criativos dentro das próprias agências brasileiras são mulheres. E, embora não existam dados oficiais que revelem as diferenças salariais e de cargos na publicidade brasileira alicerçadas no gênero, segundo o PNAD $^{13}$ de 2013, as mulheres recebiam cerca de $26,5 \%$ a menos que homens na mesma posição de trabalho.

O ser mulher na publicidade é também espaço de resistência, principalmente numa lógica de mercado profundamente guiada por padrões hegemônicos marcados pela dominação masculina que determina ideais específicos de categorias de feminilidade e do próprio papel de mulher. Cabe neste ponto então a investigação de como o mercado de beleza se comporta além da condição de mulher cisgênero, através do recente protagonismo de mulheres transexuais em peças de campanhas de beleza: quem é a mulher transexual e como ela pode ser inserida nesse contexto?

\subsection{Transexualidade, identidade e representação}

Para Stuart Hall (2003, p. 28) "essencialmente, presume-se que a identidade cultural seja fixada no nascimento, seja parte da natureza, impressa através do parentesco e da linguagem dos genes, seja constituída de nosso eu mais interior". A noção anterior descreve bem o ambiente discursivo onde a problematização do gênero visa atuar, principalmente ao

Disponível em: <http://agenciapatriciagalvao.org.br/pesquisas/>.

Disponível em: <http://www.cartacapital.com.br/sociedade/machismo-e-a-regra-da-casa-4866.html>.

Comun. \& Inf., Goiânia, GO, v. 20, n. 1, p.73-91, jan./jun. 2017 
tentar levar a compreensão do processo de construção da identidade sexual e de gênero - e a própria diferenciação entre essas categorias - para fora dos determinismos da biologia a partir da cultura.

Uma das mais pertinentes contribuições sobre as falhas de compreensão do gênero através da perspectiva biológica veio da filósofa francesa Simone de Beauvoir (1970). Ao percorrer extensamente em sua pesquisa a formação genética humana em homens e mulheres e analisar os papéis relativos e suas inversões entres diferentes espécies de machos e fêmeas na natureza, a autora declara:

[...] Uma sociedade não é uma espécie: nela, a espécie realiza-se como existência; transcende-se para o mundo e para o futuro; seus costumes não se deduzem da biologia; os indivíduos nunca são abandonados à sua natureza; obedecem a essa segunda natureza que é o costume e na qual se refletem os desejos e os temores que traduzem sua atitude ontológica. Não é enquanto corpo, é enquanto corpos submetidos a tabus, a leis, que o sujeito toma consciência de si mesmo e se realiza: é em nome de certos valores que ele se valoriza. E, diga-se mais uma vez, não é a fisiologia que pode criar valores. (BEAUVOIR, 1970, p. 56).

Já em Butler (2003), parte também dessa superação da perspectiva biológica em busca de significações culturais, as noções de sexo, gênero e desejo, só podem fazer sentido quando são inteligíveis e coerentes entre si. E, se não há substância de ser concretamente definida, Butler (2003) entende que não há ser, fazer, por trás do outro: não existiria uma essência prédiscursiva de forma natural que determinasse a cada indivíduo sua categoria de gênero antes do corpo.

O gênero, então, segundo Butler (2003), se enquadraria nas definições de performatividade, desafiando a rigidez da própria estrutura binária entre homem e mulher: não há um conjunto concreto de atributos ligados a um sexo ou a outro, não há identidade de gênero por trás de expressões de gênero, o gênero é performativamente construído por expressões diversas ao longo da vida do indivíduo a partir das influências e coerções do ambiente social e coletivo.

Butler (2003) apresenta em seu conceito noções potencialmente subversivas: aponta o corpo como instrumento de construção constante, desafiando conceitos e significados do que é masculino e feminino para além de características biológicas de sexo. Para Hall (2003, p. 27) "na situação da diáspora, as identidades se tornam múltiplas". Esse caráter de multiplicidade de identidades relacionado a deslocamentos e mudanças ganha ainda mais espaço quando se analisa sua aplicação na experiência transexual. Segundo Bento (2006): 
[...] Não existe uma "identidade transexual", mas posições de identidades organizadas através de uma complexa rede de identificações que se efetivam mediante movimentos de negação e afirmação aos modelos disponibilizados socialmente para se definir o que seja um homem/mulher de "verdade" (BENTO, 2006, p. 201).

Entende-se, portanto, que o processo de construção da identidade transexual não é fixo e passa distante de repertórios essencialistas sobre o ser e suas performances de gênero. Ainda segundo Bento (2004):

[...] Não existe transexual de verdade, mas trasexualidades. [...] A experiência transexual põe em destaque elementos que revelam o funcionamento das normas de gênero, e ao revelá-las, cria um campo contraditório de deslocamentos de fixações dessas mesmas normas (BENTO, 2004, p. 171).

Nesse panorama de incontáveis possibilidades de identidades e diferenças é que a representação pode se tornar tão importante. Para Silva (2014), a representação pode ser compreendida como um sistema de atribuição de significados, de sentidos, ligados a língua e a cultura podendo apresentar aspectos ambíguos, indefiníveis, e intrinsecamente associados a relações de poder. Woodward (2014) corrobora:

[...] A representação inclui as práticas de significações e os sistemas simbólicos por meio dos quais os significados são produzidos, posicionandonos como sujeito. É por meio dos significados produzidos pelas representações que damos sentido à nossa experiência e àquilo que somos. Podemos inclusive sugerir que esses sistemas simbólicos tornam possível aquilo que somos e aquilo no qual podemos nos tornar. A representação, compreendida como um processo cultural, estabelece identidades individuais e coletivas e os sistemas simbólicos nos quais ela se baseia fornecem possíveis respostas às questões: Quem eu sou? O que eu poderia ser? Quem eu quero ser? Os discursos e os sistemas de representação constroem os lugares a partir dos quais os indivíduos podem se posicionar e a partir dos quais podem falar (WOODWARD, 2014, p.18).

Representação e transexualidade aproximam-se mais nesse contexto. Se a condição hegemônica feminina para participação em campanhas de beleza for, por exemplo, a correspondência a um certo padrão físico específico construído pela indústria (pele clara, cabelos longos e lisos etc), a performance de gênero dos termos mulher e feminino nesta categoria podem obedecer perfeitamente a esses quesitos sem necessariamente partirem de um corpo biologicamente marcado como feminino. Butler (2003) discorre:

[...] Se há algo de certo na afirmação de Beauvoir de que ninguém nasce e sim torna-se mulher decorre que mulher é um termo em processo, um devir, um construir de que não se pode dizer com acerto que tenha uma origem ou um fim. Como uma prática discursiva contínua, o termo está aberto a intervenções e re-significações. Mesmo quando o gênero parece cristalizar-se em suas formas mais reificadas, a própria cristalização é uma prática insistente e insidiosa, sustentada e regulada por vários meios sociais. Para Beauvoir, 
nunca se pode tornar-se mulher em definitivo, como se houvesse um telos a governar o processo de aculturação e construção. O gênero é a estilização repetida do corpo, um conjunto de atos repetidos no interior de uma estrutura reguladora altamente rígida, a qual se cristaliza no tempo para produzir a aparência de uma substância, de uma classe natural do ser (BUTLER, 2003, p. 58).

Neste sentido, alguns aspectos tornam-se interessantes: se a categoria mulher é um termo em construção contínua - principalmente por conta da influência da dominação masculina como hegemônico e pelo constante estigma da mulher em vias de resistência -, e se a performatividade possibilita a reprodução de modelos de feminilidade socialmente disponíveis e potencialmente hegemônicos, quais as narrativas ideológicas por trás da participação de mulheres transexuais em campanhas femininas de beleza?

\section{METODOLOGIA}

Para construir uma análise interpretativa dos vídeos selecionados para constituição desse artigo, enxergamos no trabalho de Bordwell (2008) uma interessante instrumentalização teórico-metodológica. Para o autor, o significado de um filme é tão importante que faz com que "o espectador constantemente teste a obra por um significado maior, pelo que diz ou sugere" (BORDWEEL, 2008, p. 60, tradução nossa ${ }^{14}$ ). Desta forma, Bordwell (2008) identifica tipos de significados que podem ser observados e estão intimamente ligados aos processos de formação de sentidos.

O significado explícito busca a compreensão do ponto central, conteúdo e contexto gerais do filme. Significados explícitos são provenientes do filme como um todo e também são produto da própria comparação das cenas do produto entre si, que apresentam elementos que podem reagir de forma dinâmica de momento a momento. Já o significado implícito é uma forma mais abstrata que sugere elementos cognitivos frequentemente ligados a interpretação; há justamente um convite dessas produções para que o espectador exercite sua função interpretativa, tentando estabelecer conexões entre conteúdo e significados.

Para Bordwell (2008), embora possa parecer frequentemente que o mais coerente na busca por relações elucidativas entre temas e significados implícitos seja a exclusão de elementos concretos e explícitos do próprio filme, uma estratégia mais coesa busca por agregar significados implícitos ainda considerando o contexto geral apresentado, estreitando relações entre narrativa e estilo. A partir daí, visualizamos o significado sintomático.

\footnotetext{
14 "As an alert perceiver, the spectator is constantly testing the work for larger significance, for what it says or suggests" (BORDWELL, 2008).
}

Comun. \& Inf., Goiânia, GO, v. 20, n. 1, p.73-91, jan./jun. 2017 
Este se refere a um conjunto de características e valores da sociedade, também consideradas como ideologia. Aqui, Bordwell (2008) sugere que este tipo de significado é potencialmente um fenômeno social, fruto de um sistema cultural específico de crenças a respeito do mundo. O aspecto ideológico ressaltado por Bordwell (2008) neste tipo de significado é um fato bastante interessante para a constituição dos questionamentos do presente trabalho.

Podemos trazer as contribuições de Gramsci (1999) ao definir ideologia como "o significado mais alto de uma concepção do mundo, que se manifesta implicitamente na arte, no direito, na atividade econômica, em todas as manifestações de vida individuais e coletivas" (GRAMSCI, 1999, p. 98). É justamente sob essa perspectiva ideológica que acreditamos poder observar nos vídeos significados implícitos e explícitos sobre a transexualidade em campanhas femininas de beleza, os quais se apresentam como sintomáticos a partir do momento que valores sociais estão em jogo.

\section{APRESENTAÇÃO DOS CASOS 4.1 Caso Redken}

A Redken é uma marca norte-americana especializada em produtos para cabelos que também faz parte do conglomerado industrial da francesa L'oréal. Em 2014 a empresa foi manchete no mundo ao apresentar sua primeira "musa" transexual, a modelo brasileira Lea T, fato que fez de Lea a primeira modelo transexual a assinar um grande contrato para campanhas globais de uma marca de produtos de beleza ${ }^{15}$. Lea protagonizou em 22 de janeiro de 2015 seu primeiro vídeo para a marca publicado no Youtube. Até a finalização deste artigo o vídeo possuía 4.545 visualizações, 21 marcações como "gostei” e duas como "não gostei".

\subsubsection{Significados Explícitos}

O vídeo, que possui uma duração de 0:59 segundos, começa com uma rápida apresentação do produto e de uma descrição de Lea T seguido por foto, onde se lê "modelo e ativista anti-bullying". Logo após, um hair artist da marca aparece comentando sobre detalhes do produto e sobre a honra em trabalhar com Lea T que aparece hora sozinha na tela, hora ao seu lado, sendo por ele cuidada. Todo o vídeo sugere um clima de naturalidade, leveza e bom humor, sendo encerrado com a inserção de fotos do produto e da logomarca da empresa.

15 Disponível em: <http://fashionista.com/2014/11/lea-t-redken-campaign>. 


\subsubsection{Significados Implícitos}

O clima de naturalidade predomina no vídeo deixando perceptível a abordagem favorável ao pertencimento de uma mulher transexual numa campanha de produtos femininos. A música é eletrônica, agitada e divertida, e Lea $\mathrm{T}$ aparece hora ao fundo, hora em planos fechados, com expressões suaves e sorridente, em cenas clichês de outras campanhas do setor, como o close em que o vento movimenta seus cabelos longos e sedosos. A maquiagem é suave e ressalta os traços delicados e femininos da modelo, assim como as unhas, roupas e acessórios.

\subsubsection{Significados Sintomáticos}

Embora a contratação de Lea $\mathrm{T}$ pela Redken tenha sido amplamente divulgada, em nenhum momento as campanhas da marca se associam ao termo transexual. A descrição da modelo que é sugerida no vídeo, "modelo e ativista anti-bullying", também se repete no seu perfil de musa no site da empresa ${ }^{16}$. Importante salientar a amplitude do termo bullying. Pode associar-se a qualquer tipo de preconceito e discriminação, como homofobia, racismo, transfobia, problemas sociais, até a situações mais individualizadas de rixas entre grupos, e que é aqui citado de forma vaga, como elemento pré-discursivo, ainda que não aponte especificamente nem para o óbvio - o fato de se ter uma musa transexual como um argumento potencial para um posicionamento mais enfático quanto à diversidade sexual.

Esse fator pode tanto sugerir uma naturalização do termo mulher, como também uma estratégia da marca por maior aceitação e menos controvérsia. Visto que Lea possui características físicas que atendem facilmente aos padrões determinados pela indústria de beleza, algo que faria relação com o fator passabilidade, anteriormente citado.

\subsection{Caso Clean \& Clear}

Clean \& Clear é uma marca norte-americana de produtos skincare para cuidados dermatológicos presente em mais de 50 países. Em março de 2015 a Clean \& Clear publicou um vídeo da campanha digital "\#SeeTheRealMe"("Veja o verdadeiro eu", em tradução livre) com a participação inédita de uma transgênero, a adolescente Jazz Jennings, de 16 anos. Jennings, também norte-americana, além de protagonizar um reality show junto a sua família sobre sua vida no canal norte-americano TLC em 2015, em 2016 também lançou sua própria autobiografia, intitulada "Being Jazz: My Life as a (Transgender) Teen".

16 Disponível em: 〈http://www.redken.com/lookbook/muses-and-creators/lea-t $\rangle$. 
Além do primeiro vídeo analisado abaixo, publicado no Youtube no dia 12 de março de 2015 e que até o fechamento deste artigo possuía 4.577.349 visualizações, 5.557 "gostei" e 524 "não gostei", Jennings estreou outros cinco vídeos para o canal oficial da Clean \& Clear no YouTube.

\subsubsection{Significados Explícitos}

A narrativa do vídeo, que possui 1:06 de duração, inicia focando na própria trajetória de Jazz como transgênero, na primeira pessoa e num tom mais introspectivo. Jazz compartilha as dificuldades de crescer como transgênero, "[...] uma garota presa num corpo de garoto" (tradução livre), principalmente no que diz respeito ao ambiente escolar e as relações com outros adolescentes.

Após os 30 segundos iniciais, quando Jazz "decide fazer uma mudança, se colocar lá fora e fazer novos amigos" (tradução livre), a garota recebe um grupo de amigas e elas se arrumam para uma festa na piscina. Ao final do vídeo, Jazz compartilha que seu "eu real está feliz e orgulhoso de ser quem é, e estou apenas me divertindo sendo uma das garotas" (tradução livre) e encosta a cabeça no ombro de uma das amigas. Nos últimos segundos da campanha aparece a marca Clean \& Clear, e um convite para participar de uma discussão no Twitter da empresa.

\subsubsection{Significados Implícitos}

Nos primeiros 30 segundos da peça, quando Jazz compartilha suas dificuldades há uma composição sutil em planos abertos e fechados dando ênfase às características consideradas mais femininas de Jazz, que tem pele e olhos mais escuros, cabelos longos ao vento e gestos, roupas e acessórios considerados femininos, delicados e discretos.

Após os 30 segundos de vídeo, a música agita-se e Jazz recebe suas amigas em casa: todas reproduzem o mesmo padrão estético de cabelos longos e visual considerado feminino, delicado e discreto e juntas elas iniciam uma estereotipada rotina de beleza feminina. Fica claro aqui a performatividade do feminino como delicado, discreto e suave, do padrão de características físicas associadas ao ser menina/mulher e o pertencimento de Jazz ao grupo.

\subsubsection{Significado Sintomático}

O vídeo trata com naturalidade da experiência transexual, em termos de fácil compreensão e com grande apelo emocional. Dito isso, ele também reforça um padrão físico e performativo de mulher, com gestos e visual delicado e discreto. A escolha específica da própria

Comun. \& Inf., Goiânia, GO, v. 20, n. 1, p.73-91, jan./jun. 2017 
Jazz, inclusive, dificilmente pode ser considerada como aleatória: além do conjunto de características físicas favoráveis ao padrão da indústria de beleza, há obviamente um grande apelo em sua trajetória midiática.

\subsection{Caso Avon}

A Avon é uma empresa norte-americana de cosméticos, atualmente presente em mais de 100 países. Em 8 outubro de 2015 a Avon publicou um vídeo para o Outubro Rosa, mês marcado por campanhas que promovem a conscientização sobre o câncer de mama e sua prevenção por meio do autoexame. Nesse caso, o diferencial veio pela escolha do protagonismo da peça publicitária da campanha denominada \#EuUsoAssim: a cantora transexual Mel Gonçalves, conhecida como Candy Mel. Até o momento de finalização do presente artigo o vídeo ${ }^{17}$ possuía 303.915 visualizações, 1.657 marcações de "gostei”, e 89 marcações de "não gostei”.

\subsubsection{Significados Explícitos}

A narrativa do vídeo, que possui 0:57 de duração, inicia com o nome da campanha no centro do vídeo \#EuUsoAssim, marcado com o fundo rosa. Em seguida, Candy Mel, que é uma mulher negra de pele mais clara e assume seus cabelos crespos, aparece com um laço vetorizado rosa, que é símbolo da campanha Outubro Rosa. Com gestos que podem ser considerados femininos e delicados, a cantora então narra a importância do mês de outubro para as mulheres, e como estas possuem "um motivo a mais para se sentirem mais bonitas".

A partir daí, ela ensina como "abusar do rosa e fazer um make incrível”. Ela utiliza uma maquiagem inteira em variações de rosa e finaliza com a apresentação de sua própria imagem sem maquiagem e com maquiagem, narrando à mensagem "abuse do rosa e mostre que você também apoia essa causa". Nos segundos finais aparece a marca Avon acompanhada do texto "beleza que faz sentido".

\subsubsection{Significados Implícitos}

Neste nível de interpretação percebe-se a importância da utilização da cor rosa, tanto no cenário, maquiagem, roupa e acessórios, traduzindo um significado implícito tanto de feminilidade quanto de reforço à ideia do Outubro Rosa. A escolha do enquadramento possibilita perceber a cantora como se estivesse frente a um espelho, com o olhar direto para câmera, traduzido assim uma ideia de aproximação com o telespectador, enquanto a narração é

17 Disponível em: 〈https://www.youtube.com/watch?v=ubYp8Hcl1HQ〉. 
feita de forma coloquial, postura similar à utilizada por blogueiras em vídeos que visam ensinar mulheres a se maquiar. Fica então fortemente perceptível a performatividade do feminino e da naturalização e do pertencimento da Mel Gonçalves a este lugar.

\subsubsection{Significados Sintomáticos}

O vídeo publicitário em nenhum momento identifica a cantora como transexual. Este fator pode tanto destacar uma naturalização do termo mulher, posto que a mesma assim se identifica no decorrer do vídeo quando narra "em outubro toda mulher tem um motivo especial para se sentir ainda mais linda", como também a aposta da marca na trajetória da cantora como pessoa pública, como uma estratégia que aposta na passabilidade e evita constrangimentos, podendo inviabilizar também um contexto político de luta contra a transfobia.

\subsection{Caso MAC Cosmetics}

A $M A C$ é uma empresa de maquiagem e cosméticos fundada em Toronto considerada uma das maiores e mais importantes marcas globais desse segmento. Em novembro de 2014 a marca canadense lançou uma campanha com o propósito de escolher o casting que iria estrelar a sua nova coleção de outono de 2015, \#MACnificentMe, composta por pessoas comuns. Neste artigo nós analisamos o vídeo da transexual Gewinnerin Trésor, uma das seis pessoas selecionadas para a campanha. Até a finalização do presente artigo o vídeo ${ }^{18}$, publicado no Youtube no dia 8 de outubro de 2015, possuía 47.232 visualizações, 284 pessoas marcações como "gostei" e 30 como "não gostei".

\subsubsection{Significados Explícitos}

A narrativa do vídeo possui 1:49 e tem início com a presença da Trésor falando em primeira pessoa sobre suas dificuldades em se sentir bonita. Trésor, que é de pele e olhos claros, aparece com os cabelos lisos e medianos presos em coque. Seus gestos podem ser considerados discretos e delicados ao mesmo tempo em que ela se apresenta com vestimentas sóbrias e sem maquiagem, o que esteticamente poderia ser associado a um visual considerado socialmente como masculino.

No decorrer do vídeo ela é maquiada e troca de figurino, com um vestido dramático e acessórios como meia-calça, salto alto, colar, unhas longas e pintadas, e então registra-se uma transição de gênero marcante para o que é considerado feminino. Ao fim, aparecem duas fotos

18 Disponível em: 〈https://www.youtube.com/watch?v=RV3FdaVTRd>.

Comun. \& Inf., Goiânia, GO, v. 20, n. 1, p.73-91, jan./jun. 2017 
de Trésor, um antes e depois com a aparência no que poderia ser descrito como mais feminizada, e logo em seguida o nome da campanha \#MACnificentMe.

\subsubsection{Significados Implícitos}

Está implícita a mensagem de aproximação que o vídeo tenta trazer, ao utilizar de pessoas comuns e não celebridades e modelos com padrão físico totalmente estabelecido pela indústria - uma ironia, visto que a personagem passa por uma "transformação", e ainda assim possui características hegemônicas, como a pele branca e olhos claros. Trésor inicia o vídeo com o corpo considerado mais próximo ao masculino, expressões mais contidas e roupas discretas; a evolução da narrativa aproxima Trésor de elementos performáticos que são considerados femininos a partir de uma lógica binária, com os movimentos, a roupa, cabelo, maquiagem, o olhar para a câmera e o posicionamento.

\subsubsection{Significados Sintomáticos}

Trésor não traz indícios óbvios de transexualidade à princípio, visto que em primeiras impressões não apresenta características associadas a passabilidade de uma estética e performatividade consideradas femininas. O termo transexualidade tampouco é citado no vídeo, apesar de inserido num contexto óbvio de diversidade teoricamente incitado pela campanha. Este vídeo inclusive só foi inserido no presente artigo após a pesquisa do nome de Trésor em outros sites ${ }^{19}$, onde se confirma sua transgeneriedade. Destacamos também a transição pouco sutil quanto a estética de "masculino" e "feminino", algo que, além de reforçar padrões estéticos relacionado a gênero, fortalece também a própria estrutura binária da sociedade, de encaixar-se apenas em duas categorias de gênero bem delimitadas.

\subsection{Caso L'oréal}

A L'oréal é uma empresa multinacional francesa que atua em aproximadamente 130 países. Em 2016 a empresa teve como primeira porta-voz transexual no mundo a modelo brasileira transgênero, Valentina Sampaio. Valentina iniciou sua trajetória na marca com a aparição num vídeo ${ }^{20}$ que celebra o Dia Internacional da Mulher, publicado no dia 8 de Março de 2015. O vídeo foi recorde de audiência e em apenas 3 horas de exibição contabilizou 1,5

\footnotetext{
19 Disponível em: 〈http://www.teenvogue.com/story/transgender-writer-makeup-journey> $<$ http://www.teenvogue.com/story/mac-cosmetics-fall-campaign-winner-interview $>$.

20 Disponível em: <https://www.youtube.com/watch?v=3J8CiwL4BC>.
}

Comun. \& Inf., Goiânia, GO, v. 20, n. 1, p.73-91, jan./jun. 2017 
milhões de visualizações no Facebook oficial da marca. ${ }^{21}$ Já no Youtube, até o momento de finalização do artigo o vídeo da campanha havia sido visualizado 111.336 vezes, recebeu 827 “gostei” e 54 "não gostei”.

\subsubsection{Significados Explícitos}

O vídeo possui uma duração de 0:56 segundos e inicia com Valentina entrando num quarto, sentando em frente a uma penteadeira. Valentina é alta, branca, magra, com olhos claros e longos cabelos loiros e lisos. Seus gestos são socialmente considerados femininos e delicados, assim como sua roupa e maquiagem. Ao mesmo tempo em que uma música suave inicia, Valentina conta em primeira pessoa sua história, num tom de desabafo e confissão, como uma mulher que se sente bonita e se arruma para um dia especial, o Dia Internacional da Mulher.

A cena pretende apresentar uma situação cotidiana da vivência feminina, onde a mulher se embeleza para sair e também ressalta a proposta da marca em valorizar "todas" as mulheres. Ao final do vídeo, Valentina exibe sua carteira de identidade, ressaltando sua transexualidade e exaltando seu novo registro civil e sua satisfação em passar seu primeiro dia da mulher "oficialmente como uma", em suas palavras, que fazem menção a sua real identidade de gênero representada no documento oficial por meio do nome feminino.

\subsubsection{Significados Implícitos}

Está implícita na narrativa a importância do estereótipo da mulher como símbolo de beleza e feminilidade, onde o arrumar-se, e até mesmo a preocupação da protagonista com a aparência remete a ideia do ser mulher. Valentina ocupa com muita naturalidade esse espaço e fica claro o quanto suas características físicas estão diretamente relacionadas a esse pertencimento.

\subsubsection{Significados Sintomáticos}

Nesse momento considera-se como sintomática a possível naturalização da mulher transexual, aqui explicitada no ato de comemorar o Dia da Mulher, algo comumente associado apenas às mulheres cisgênero. Contudo, é perceptível, por se tratar da própria $L$ 'óreal, o quanto Valentina reproduz um padrão físico hegemônico de beleza, com 'aura de sonho', como ressalta Lipovetski (1989). Ao fim do vídeo, Valentina ressalta sua felicidade em comemorar seu

21 Disponível em: <http://oglobo.globo.com/ela/beleza/ao-investir-em-questoes-de-genero-nao-fugir-depolemica-comerciais-do-mercado-de-cosmeticos-viralizam-na-internet-19863783>. 
primeiro Dia da Mulher "oficialmente" como uma, apresentando então seu documento de identidade com o nome feminino.

Vale problematizar o quanto a mudança do registro civil é de fato uma luta real e constante da comunidade transexual, principalmente por conta do estigma de patologia que a ronda. Atualmente, a mudança do nome nos documentos requer uma longa jornada judicial que pode ou não ser favorável ao requerente. Um avanço nesse sentido foi o Decreto $\mathrm{n}^{\circ} 8727$, ou Lei do nome social, sancionada pela então Presidenta da República, Dilma Roussef em 2016 que permite o uso de nome social por travestis e pessoas transexuais no serviço público.

\section{CONCLUSÃO}

Em termos de contextos aos quais mulheres transexuais foram inseridas em campanhas femininas de beleza, fica claro que a maioria das peças apresentou a transexualidade com tom de naturalidade, uma jornada, sem qualquer aspecto humorístico ou exótico, destacando, muitas vezes, a própria trajetória particular de vida de cada uma dessas mulheres. Na maioria dos casos a narrativa apostou em um aspecto humanizado com grande apelo emocional. Essa naturalização da condição de mulher alcança, inclusive, pontos que podem ser considerados inéditos e com grande potencial de visibilidade, como a participação em campanhas do Outubro Rosa, no caso da Avon, ou em comemoração ao Dia da Mulher, no caso da L'oréal.

Por outro lado, fica claro que na maioria dos casos as mulheres transexuais escolhidas reforçam o padrão hegemônico de beleza feminina. As peles são mais claras, e a performatividade de gênero quase em sua totalidade traz corpos magros, gestos, feições, figurino e maquiagem discretos, delicados e invariavelmente relacionados aos estereótipos do que é esteticamente considerado feminino, performatizado por mulheres. Em termos de raça e etnia, ressaltamos as participações de Lea T e Mel Gonçalves, mulheres negras e celebridades, sendo Mel Gonçalves uma mulher negra que assume seu cabelo afro. $\mathrm{O}$ uso de celebridades também é outro fator de destaque.

Em termos estéticos gerais, novamente voltamos ao termo passabilidade adicionado a uma lógica de mercado: o corpo não precisaria ser biologicamente feminino, desde que sua performance como feminino reflita os padrões hegemônico já em vigor, padrões não só estéticos como vigentes na própria definição cultural e comportamental hegemônica de ser “mulher”. É possível pensar que sim, a indústria de beleza pode significar um interessante processo representativo quanto à transexualidade e o pertencimento da mulher transexual em suas 
口

campanhas, por muitas vezes travando um diálogo potencial com a diversidade, porém, é preciso, paralelamente, problematizar esses mesmos espaços.

As peças analisadas podem demonstrar a produção potencial de um tipo específico de mulher transexual, como também um ideal estético de "diversidade" ao construir um modelo representativo específico em suas produções: passam a reforçar com frequência não só "um ser mulher", como algo tão potencialmente contraditório quanto um "padrão ideal de diversidade" ou até mesmo um padrão de "mulher transexual de verdade", uma "diversidade" que atende a critérios e a uma permissividade observada, vigiada e tolhida.

Portanto, reconhecemos aqui, e apropriando-nos da noção de "guerra de posições culturais" de Hall (2003), que as campanhas femininas de beleza protagonizadas por mulheres transexuais neste artigo analisadas, ainda que em diversos aspectos sirvam a um modelo contraditório e hegemônico que beneficia o mercado, podem abrir um interessante debate sobre questões de gênero e diversidade. Nem vitória, nem derrota, essas campanhas, mesmo que potencialmente problemáticas, podem indicar a abertura de um espaço, um caminho a ser desenvolvido, onde a própria natureza humana em sua multiplicidade de maneiras de ser possa ser representada, e que na dinâmica entre o hegemônico e a resistência, a resistência possa, enfim, ser mais que resistir: existir.

\section{REFERÊNCIAS}

BEAUVOIR, S. O Segundo Sexo 1: fatos e mitos. São Paulo: Divisão Europeia do Livro, 1970.

BENTO, B. A reinvenção do corpo: sexualidade e gênero na experiência transexual. Rio de Janeiro: Garamond, 2006.

Da transexualidade oficial às transexualidades. In: CARRARA, S.; GREGORI, M. F.; PISCITELLI, A. (Org). Sexualidade e saberes: convenções e fronteiras. Rio de Janeiro: Garamond, 2004.

BORDWELL, D.; THOMPSON, K. Film Art: an introduction. New York: McGraw-Hill, 2008.

BOURDIEU, P. A Dominação Masculina. Rio de Janeiro: Bertrand Brasil, 1999.

BUTLER, Judith P. Problemas de gênero: feminismo e subversão da identidade. Rio de Janeiro: Civilização Brasileira, 2003.

GRAMSCI, A. Cadernos do cárcere. Rio de Janeiro: Civilização Brasileira, 1999. 
HALL, S.; SOVIK, L. (Org.). Da diáspora: identidades e mediações culturais. Belo Horizonte: Editora UFMG, 2003.

LIPOVETSKY, G. O Império do Efêmero: a moda e seu destino nas sociedades modernas. São Paulo: Companhia das Letras, 1989.

MORAES, D. Ativismo em rede: comunicação virtual e contrahegemonia. In: A batalha da mídia: governos progressistas e políticas de comunicação na América Latina e outros ensaios. Rio de Janeiro: Pão e Rosas, 2009.

(Org.). Mutações do visível: da comunicação de massa à comunicação em rede. Rio de Janeiro: Pão e Rosas, 2010.

SILVA T. T. A Produção Social da Identidade e da Diferença. In: SILVA, T. T. (Org.). Identidade e Diferença: A perspectiva dos Estudos Culturais. Petrópolis: Editora Vozes, 2007.

WILLIAMS, Raymond. Marxismo e Literatura. Rio de Janeiro: Zahar, 1979.

WOODWARD, K. Identidade e Diferença: Uma Introdução Teórica e Conceitual. In: SILVA, T. T. (Org.). Identidade e Diferença: A perspectiva dos Estudos Culturais. Petrópolis: Editora Vozes, 2007. 